\title{
Review: the extended tip spatula is more effective than the Ayre's spatula for detecting karyosis in cervical smears
}

Martin-Hirsch P, Lilford R, Jarvis G, et al. Efficacy of cervical-smear collection devices: a systematic review and meta-analysis. Lancet 1999 Nov 20;354:1763-70.

\section{QUESTION: In women having cervical smears, what devices are most effective for obtaining adequate smears and detecting disease?}

\section{Data sources}

Studies were identified by searching Medline (to July 1997), handsearching 16 journals, and scanning the references of relevant articles.

\section{Study selection}

Studies were selected if they were randomised controlled trials (RCTs) that reported rates of endocervical cells collected, detection of dyskaryosis, or adequate smears.

\section{Data extraction}

Data were extracted on methods of randomisation, participant characteristics, source of recruitment, proportions of smears with endocervical cells and dyskaryotic cells, and proportion of adequate smears.

\section{Main results}

34 RCTs met the selection criteria. The method of randomisation was described in 27 studies; 16 studies reported inadequate methods of randomisation. The extended tip spatula led to greater rates of endocervical cell collection $\{\mathrm{p}<0.001\} *$ and detection of dyskaryosis $\{\mathrm{p}<0.001\}^{*}$ than did the Ayre's spatula (table). The spatula and Cytobrush led to greater rates of endocervical cell collection than did the spatula alone $\{\mathrm{p}<0.001\}^{*}$, the spatula and swab $\{\mathrm{p}<0.001\}^{*}$, the Cervexbrush $\{\mathrm{p}<0.001\}^{*}$, or the Baynebrush $\{\mathrm{p}<0.001\}^{*}$ (table). The spatula and Cytobrush obtained more adequate smears than did the Cervexbrush $\{\mathrm{p}<0.001\}$ * Statistical heterogeneity $\{\mathrm{p}<0.001\}^{*}$ was present in most of these comparisons (table).

\section{Conclusions}

The extended tip spatula is more effective than the Ayre's spatula for collecting endocervical cells and detecting karyosis. The combination of spatula and
Cytobrush collects more endocervical cells than do the spatula alone, the spatula and swab, the Cervexbrush, and the Baynebrush and obtains more adequate smears than does the Cervexbrush.

*p Values calculated from data in article.

\section{COMMENTARY}

The cervical smear is 1 of the most successful cancer detection methods available Despite its success, concerns have been raised about its false negative rate. In studies in which the cervical smear was done under optimal conditions, the false negative rate has ranged from $0 \%$ to $29.7 \% .{ }^{1}$ Approximately one third of all false negative cervical smear results occur because of errors in sampling and interpretation. ${ }^{2}$ Squamous intraepithelial lesions tend to be focal, which means that adequate sampling of the entire transformation zone is important. The optimal technique includes sampling the entire ectocervix and the endocervical canal. The presence of endocervical cells on the cervical smear makes it likely that the transformation zone has been adequately sampled.

The meta-analysis by Martin-Hirsch $e t$ al shows that certain devices are more effective than others for collecting adequate specimens. The spatula, in combination with the Cytobrush, provides optimal sampling. The extended tip spatula is more effective than the Ayre's spatula for collecting endocervical cells. In US, most clinicians use the Ayre's spatula with the Cytobrush, although some use the Cervexbrush alone or the Ayre's spatula with a cotton swab. This study supports the continued use of the Ayre's spatula and Cytobrush. If a single sampling tool is required because of resource constraints, the extended tip spatula is preferred. Obtaining an adequate sample is operator dependent: however, certain devices make it more likely that an adequate sample will be collected. Clinicians should do periodic audits of their cervical smear results to assess the frequency of endocervical cells on their smears. The Ayre's spatula is no longer acceptable as the sole collection device for cervical smears.

Jim Nuovo, MD Joy Melnikow, MD, MPH University of California, Davis Sacramento, California, USA

1 Koss LG. Cervical (Pap) smear. New directions. Cancer 1993;71(4 suppl):1406-12.

2 Sawaya GF, Grimes DA. New technologies in cervical cytology screening: a word of caution. Obstet Gynecol 1999;94:307-10.

The effectiveness of cervical smear collection devices $†$

\begin{tabular}{|c|c|c|c|c|c|}
\hline Outcomes & Heterogeneity & Comparison & $\begin{array}{l}\text { Weighted } \\
\text { proportions }\end{array}$ & RBI (95\% Cl) & NNS (Cl) \\
\hline \multirow[t]{5}{*}{ Endocervical cells } & $p<0.001$ & Ext tip $v$ Ayre's & $66 \%$ v $46 \%$ & $50 \%$ (30 to 73$)$ & 6 (4 to 8$)$ \\
\hline & NS & $\mathrm{Sp}+\mathrm{Cy} v \mathrm{BB}$ & $92 \% \vee 90 \%$ & $2 \%(1$ to 4$)$ & 46 (30 to 102$)$ \\
\hline & $p<0.001$ & $\mathrm{Sp}+\mathrm{Cy} v \mathrm{Sp}$ & $100 \%$ v $87 \%$ & $17 \%(10$ to 23$)$ & 8 (6 to 12$)$ \\
\hline & $\mathrm{p}<0.001$ & $\mathrm{Sp}+\mathrm{Cy} v \mathrm{Sp}+\mathrm{Sw}$ & $95 \%$ v $79 \%$ & $24 \%$ (14 to 35$)$ & $7(5$ to 11$)$ \\
\hline & $p<0.001$ & $\mathrm{Sp}+\mathrm{Cy} v \mathrm{CB}$ & $94 \%$ v 89\% & $5 \%(2$ to 9$)$ & 21 (14 to 49$)$ \\
\hline Adequate smears & NS & $\mathrm{Sp}+\mathrm{Cy} v \mathrm{CB}$ & $97 \%$ v $96 \%$ & $1 \%(1$ to 2$)$ & 83 (56 to 159) \\
\hline Dyskaryotic cells & $\mathrm{p}<0.001$ & Ext tip $v$ Ayre's & $10 \% \vee 8 \%$ & $17 \%$ (7 to 27$)$ & 50 (28 to 270$)$ \\
\hline
\end{tabular}

†Ayre's = Ayre's spatula; $\mathrm{BB}=$ Baynebrush; $\mathrm{CB}=$ Cervexbrush; $\mathrm{Cy}=$ Cytobrush; Ext tip $=$ extended tip spatula; NNS $=$ number needed to screen; $\mathrm{NS}=$ not signifcant; $\mathrm{Sp}=$ spatula; $\mathrm{Sw}=$ swab. Other abbreviations defined in glossary; RBI, NNS, and Cl calculated from data in article.

Sources of funding: Well-Being Charity and Royal College of Obstetricians and Gynaecologists.

For correspondence: Dr P Martin-Hirsch, Department of Obstetrics and Gynaecology, St.Mary's Hospital, Manchester M13 OJH, UK. Fax +44(0)1612766107. 